\title{
Intranodal Palisaded Myofibroblastoma of Inguinal Region, a Rare Benign Lesion: Case Report
}

\author{
${ }^{1}$ Minakshi Gulia ${ }^{2}$ Neelam Sood

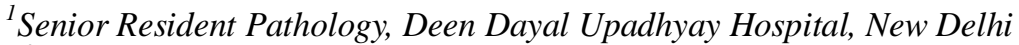 \\ ${ }^{2}$ Consultant and Head of Department of Pathology and Lab Medicines, \\ Deen Dayal Upadhyay Hospital, New Delhi
}

\begin{abstract}
:
Intranodal Palisaded Myofibroblastoma is a benign lesion characterized by intranodal proliferation of cells with myofibroblastic origin. It shows striking histopathological features characterized by spindle cells with nuclear palisading, intralesionalhaemorrhage, amianthoid fibers, intracellular and extracellular fuchsinophilic bodies, abundance of mast cells and compressed remnant lymphoid tissue at the periphery. Immunohistochemically the spindle cells are Vimentin, Beta catenin and SMA positive and are negative for S 100, with low ki-67 index. Palisaded Myofibroblastoma is a rareintranodal entity and it needs to be differentiated from Schwannoma which it closely resembles. Here we report a case of a 52 years old male patient who presented with mass in the left inguinal region.
\end{abstract}

Keywords: Intranodal Palisaded Myofibroblastoma(IPM), AmianthoidFibers, SMA, Vimentin, Masson's Trichrome, Hematoxylin\&Eosin (H\&E), Immunohistochemistry (IHC)

\section{INTRODUCTION}

Palisaded myofibroblastoma, also known as benign, lymph node based myofibroblastic tumor of unknown pathogenesis or intranodal hemorrhagic spindle cell tumor with amianthoid fibers1-4. The tumor is found almost exclusively in inguinal lymph nodes although fewcases have been reported in mediastinal, pelvic and axillary lymph nodes. Tumor consist of cellularproliferation of cytologically bland spindle cells arranged in short fascicles and whorls, replacing thesubstance of lymph node and irregular knots of collagen bundles (the amianthoidfibres with a crystalline appearence). The spindle cells have elongated nuclei that often show nuclear palisading similar to that of nerve sheath tumor.The cells have eosinophilic and tapered cytoplasm giving them a myoidquality.There are perinuclear intracytoplasmic hyaline globules, extravasatedred blood cells and proliferation of haemosiderin containing histiocytes in the lymph node1-4.Mast cells are abound in this lesion.

It is postulated that the core of amianthoid fibers represents interstitial matrix degraded by the mast cells while the peripheral palisaded spokes are the result of Vimentin and Smooth muscle actin laiddown by proliferating myofibroblasts2. There is a characteristic antigen profile which shows homogenous expression of Vimentin, Beta catenin andSmooth muscle actin as well as lack of Desmin.

\section{CASE REPORT}

The physical examination of a 52 years old male patient who presented with a slow growing mass in the Left inguinal region, revealed a firm, non-tender and mobile swelling measuring $4 \times 2$ $\mathrm{cm}$.Radiological finding were suggestive of a soft tissue mass in the inguinal region with subcentric and enlarged lymph nodes surrounding the lesion.

Fine needle aspiration cytology (FNAC) of the mass revealed features suggestive of stroma rich spindle cell lesion.Histopathological correlation was advised. The mass was excised and sent for histopathological examination.

Grossly,single globular encapsulated greyish white soft tissue mass was received measuring $6 \times 4 \times 3$ $\mathrm{cm}$. The cut section was solid, greyish-white with patchy red-brown areas. The microscopic examination showed spindle cell proliferation along with homogenous eosinophilic deposition, haemosederin-laden macrophages and extravasated erythrocytes.Spindle cell nuclei displayed a patchy pattern of palisading. The collagen accumulation were recognised as "amianthoid fibers" exhibiting irregular pattern of distribution and forming stellate structure in some areas.No mitosis, 
MinakshiGulia \& NeelamSood, "Intranodal Palisaded Myofibroblastoma of Inguinal Region, a Rare Benign Lesion: Case Report"

necrosis or atypia was found in the lesion which was surrounded by compressed lymphoid tissue and a fibrous capsule.

On Masson's Trichrome staining,the spindle cells were identified as smooth muscle and the amianthoidfibres (homogenous eosinophilic accumulation) were positive for collagen. On immunohistochemistry, the tumor cells displayed positive reaction for Vimentin, Smooth muscle actin (SMA)and Beta-catenin and negative reaction for S-100, CyclinD1,Epithelial Membrane Antigen (EMA), Cytokeratin,Caldesmon and Calponin. The ki-67 index of proliferation was below 1\%.In view of the above findings the casewas diagnosed as Intranodal Palisaded Myofibroblastoma.

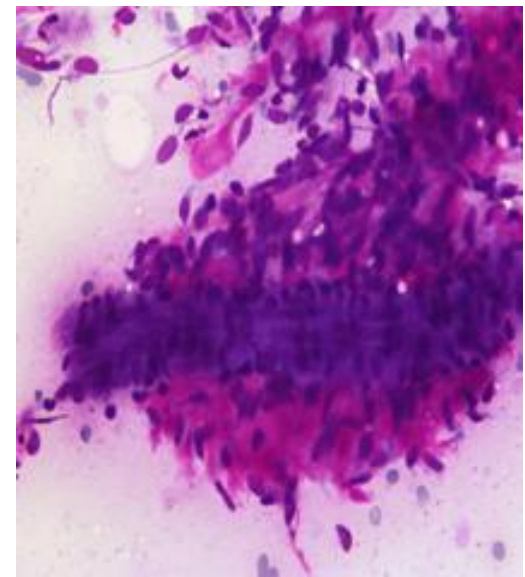

(A)

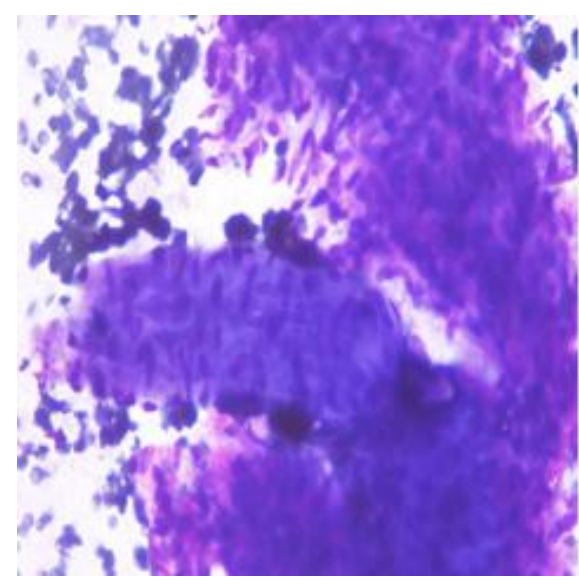

(B)

Figure1. Microphotographs of Fine needle aspiration cytology

(A) Amianthoid like structures with dense pink central stroma with central vessel, surrounded by ovoid to spindle cells in gentle swirls ( $H \& E x 400)$.

(B) Dense pink staining stroma with metachromatic hue with peripheral calcification (MGG $x 400$ ).

\section{DISCUSSION AND REVIEW OF LITERATURE}

There have been few case reports of Intranodal Palisaded Myofibroblastoma (IPM) in inguinal, pelvic, retroperitoneal, axillary and submandibular lymph nodes mainly, where it is described as a rare benign primary mesenchymal neoplasm originating from differentiated smooth muscle cells andmyofibroblasts.

IPM was first described in English literature in 1968, although back then it was not classified as IPM. This current name was adopted because of its reflection of a myofibroblastic origin as well as prominent palisaded spindle cells histologically ${ }^{1-6}$.

It is essential to differentiate IPM from other soft tissue tumors such as Schwannoma, Intranodal leiomyoma, Kaposi's sarcoma, inflammatory pseudotumor, solitary fibromastocytic tumor, angiomyomatous hamartoma and metastatic spindle cell lesions in the lymph node. The clinical history, examination, characteristic histological and immunohistochemical features aid in the correct diagnosis of IPM. Schwannoma is quite uncommon in the inguinal region and it is positive for S 100 which differentiates it from IPM. Absence of Ebstein Barr Virus (EBV) DNA, negative immunostaining for HHV 8 and immunocompromised status favors the diagnosis of IPM rather than Kaposi's sarcoma.Also, there are no slit-like vascular channels, extravasated RBCs and no hyaline globules as seen in Kaposi's sarcoma ${ }^{2-9}$.

Although the previous studies have provided comprehensive analysis of the characteristic clinicopathologic features of IPM, its pathogenesis remains unknown. In order to decipher a key to itsetiopathogenesis, Leskin et al did a clinicopathologicimmunohistochemical and molecular genetic study in 18 cases of this rare entity, 15 from inguinal lymph nodes, one neck node and two undesignated lymph nodes. Screening was done for mutation in the beta-catenin gene glycogen synthase kinase-3(B) phosphorylation mutational hotspot region in Escon-3 using PCR amplification and sanger sequencing. The results demonstrated that mutational activation of the beta-catenin 1 (CTNNB1) gene is likely a pivotal event in the pathogenesis of IPM. Based on their study, IPM could be added to the list of mesenchymal neoplasms driven by gain of function CTNNB1 mutation ${ }^{5}$.

Most of the cases have been reported in Inguinal lymph node where the tumor cells were positive forSMA and Beta catenin but negative for Desmin,CD-34,S-100 and CD 117 by immune histo 
MinakshiGulia \& NeelamSood, "Intranodal Palisaded Myofibroblastoma of Inguinal Region, a Rare Benign Lesion: Case Report"

chemical (IHC) staining. A higher concentration of myofibroblasts in the inguinal lymph nodes as compared to other lymph nodes in the body, due to increased drainage area and function, might explain its more common occurrence in the inguinal region.

Among the rare sites of occurrence, Sagar et al5 reported a case with characteristic clinicopathological and IHC profile originating from retroperitoneum (an unusual origin) ${ }^{10}$. Creager reported a case of recurrent IPM in a 49yr old woman, who had cadaveric renal transplantation, the recurrent IPM presented with metaplastic bone formation ${ }^{11}$.

Hence in presence of intranodal spindle cell proliferative lesion IPM always needs to be considered and ruled out by employing full spectrum of IHC.

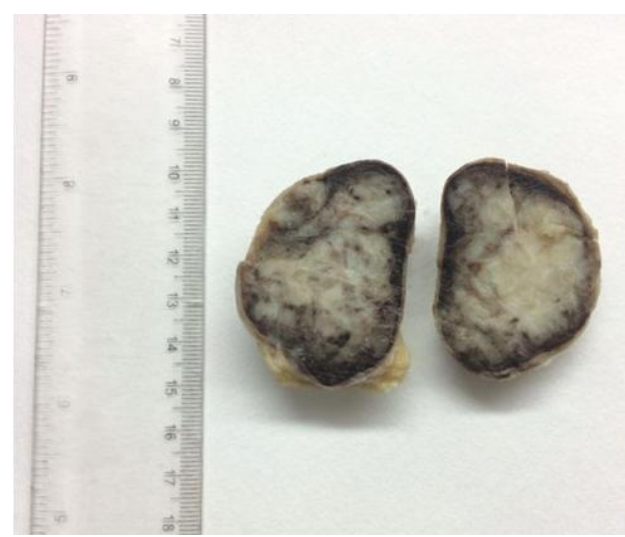

(A)

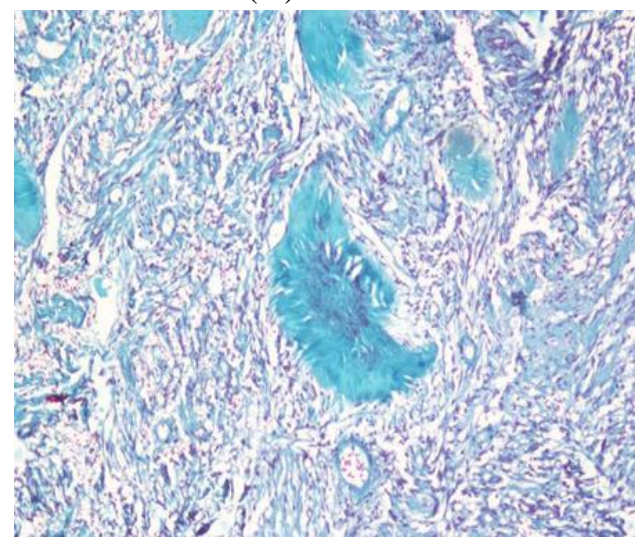

(C)

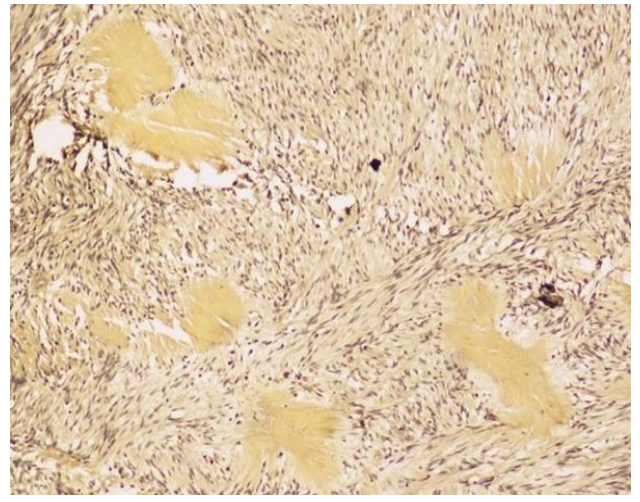

(E)

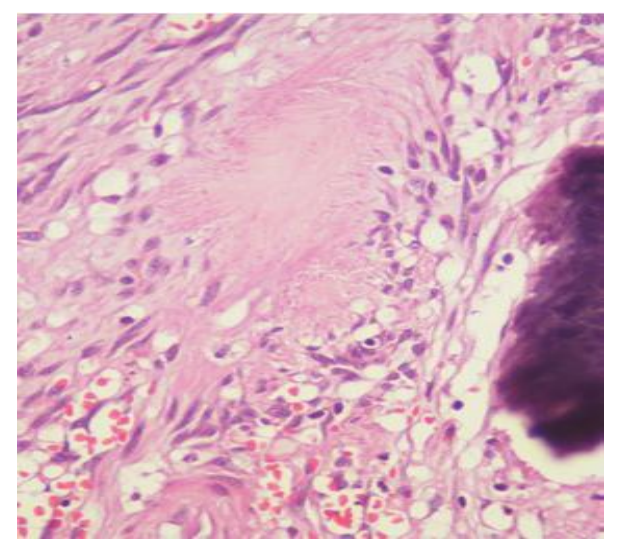

(B)

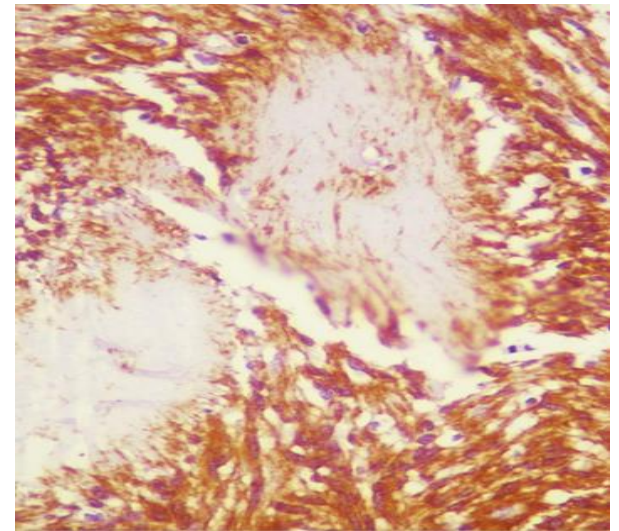

(D)

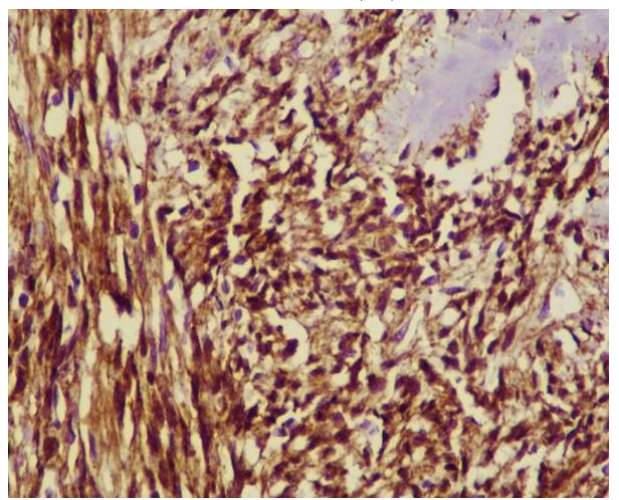

(F)

Figure2.

(A) Cut section of gross specimen of Inguinal lymph node.

(B) Microphotograph showing spindle cell proliferation in a palisading pattern around Amianthoidfibers(left) and peripheral calcification (right) (H\&E $x$ 400).

(C) Trichrome stain highlighting the differential staining pattern of amianthoidfibers $(x 400)$

(D) Strong expression of Smooth muscle actin (SMA) in spindle cells (SMA.Biocare .IgG2a, RTUx400).

(E) Reticulin stain enhancing the peripheral stellate appearance of amianthoidfibers $(x 400)$.

(F) Strong nuclear expression of Beta catenin in spindle cells (x400). 
MinakshiGulia \& NeelamSood, "Intranodal Palisaded Myofibroblastoma of Inguinal Region, a Rare Benign Lesion: Case Report"

\section{REFERENCES}

[1] Kandemir NO, Barut F, Ekinci T, Karagulle C Ozdamar SO. Intranodal palisaded myfibroblastoma (intranodalhemorrhagic spindle cell tumor with amianthoidfibers):A case report and literature review. DiagnPathol 2010; 5:12

[2] Weiss SW, Gnepp DR, Bratthauer GL. Palisaded myofibroblastoma: A benign mesenchymal tumor of lymph node. Am J SurgPathol 1989; 13:341-346.

[3] Nguyen T, Eltorky MA. Intranodal palisaded myofibroblastoma. Arch Pathol Lab Med 2007; 131:306-310.

[4] Bigotti G, Coli A, Mottolese M, Di Filippo F. Selective location of palisaded myofibroblastoma with amianthoid fibres. J ClinPathol 1991;44:761-764.

[5] Laskin WB1, Lasota JP, Fetsch JF, Felisiak-Golabek A, Wang ZF, Miettinen M. Intranodal palisaded myofibroblastoma: another mesenchymal neoplasm with CTNNB1 (b-catenin gene) mutations: Clinicopathologic, immunohistochemical, and molecular genetic study of 18 cases. Am J SurgPathol 2015; 39:197-195.

[6] Kleist B, Poetsch M, Schmoll J. Intranodal palisaded myofibroblastoma with overexpression of cyclin D1. Arch Pathol Lab Med 2003;127:1040-1043

[7] Cosenza U, Galati G, Zofrea P, et al. Clinical and biological features of an intranodal Palisaded myofibroblastoma. Anticancer Res 2006; 2349-2352.

[8] Suster S, Rosai J. Intranodalhemorrhagic spindle-cell tumor with amianthoidfiber: Report. Of six cases of a distinctive mesenchymal neoplasm of the lnguinal region that simulates Kaposi's sarcoma. Am J SurgPathol 1989; 13:347-357.

[9] Lee JY, Abell E, Shevechik GJ. Solitary spindle cell tumor with myoid differentiation of the lymph node. Arch Pathol Lab Med 1989;113:547-50

[10] Sagar J, Vargiamidou A Manikkapurath H. Intranodal palisaded myofibroblastoma originating from retroperitoneum: An unusual origin. BMC ClinPathol 2011;11:7 doi:10.1186/1472-689011-7

[11] Creager AJ, Garwacki CP. Recurrent intranodal palisaded myofibroblastoma with metaplastic bone formation. Arch Pathol Lab Med 1999; 123:433-436.

Citation: Minakshi G, Neelam S. Intranodal Palisaded Myofibroblastoma of Inguinal Region, a Rare Benign Lesion: Case Report. International Journal of Research Studies in Medical and Health Sciences. 2017;2(1):25-28.

Copyright: () 2017 Minakshi G, Neelam S. This is an open-access article distributed under the terms of the Creative Commons Attribution License, which permits unrestricted use, distribution, and reproduction in any medium, provided the original author and source are credited. 